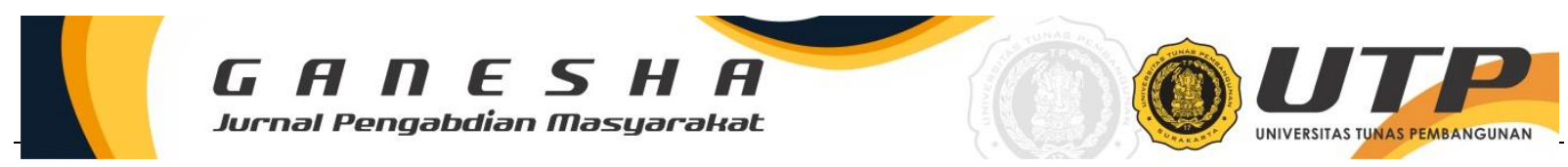

\title{
PEMETAAN EKONOMI UNTUK MENDAPATKAN STRATEGI PENINGKATAN INDUSTRI KREATIF DI DESA JAJARWAYANG BOJONG PEKALONGAN
}

\author{
Wahidatul Maghfiroh', M. Haikal Hadiyatullah², Hendri Hermawan Adinugraha ${ }^{3}$ \\ 1,2,3 IAIN Pekalongan \\ Email : wahidatulmaghfiroh@gmail.com
}

\begin{abstract}
Abstrak
Perkembangan industri kreatif di desa Jajarwayang Bojong Pekalongan sangat lambat, dari tahun ke tahun tidak ada data yang menunjukan kenaikan yang signifikan, bahkan belakangan dianggap stagnan. Masyarakat setempat belum mengetahui cara untuk mengembangkan industri ini, padahal, masyarakat Jajarwayang sangat heterogen dalam hal pekerjaan, diketahui ada beberapa pekerjaan yang masuk dalam industri kreatif, seperti halnya; produsen jeans, buruh, produsen tempe. Harus ada pemetaan yang valid agar terciptanya peningkatan industri kreatif di desa Jajarwayang, selain pemetaan, juga harus dibuat strategi yang tepat agar dapat memnuhi angka peningkatan yang drastis, guna mewujudkan kesejahteraan masyarakat dan juga meningkatkan daya saing di sector ekonomi kreatif.
\end{abstract}

Kata Kunci: Pemetaan ekonomi, industri kreatif, peningkatan

\begin{abstract}
The development of creative industries in the village of Jajarwayang Bojong Pekalongan is very slow, from year to year there is no data showing a significant increase, even later considered stagnant. The local community does not know yet how to develop this industry, whereas, jajarwayang community is very heterogeneous, it is known that there are some jobs that enter the creative industry, as well as; jeans manufacturers, laborers, tempe manufacturers. There must be a valid mapping in order to create an increase in creative industries in jajarwayang village, in addition to mapping, the right strategy must also be made in order to achieve a drastic increase in the number of improvements, in order to realize the welfare of the community and also increase competitiveness in the creative economy sector.
\end{abstract}

Keywords: Economic Mapping, Creative industry, Improvement

\section{PENDAHULUAN}

Ekonomi menjadi salah satu hal pokok dalam kesejahteraan suatu desa. Suatu desa dinilai maju apabila perekonomiannya dapat berkembang dengan baik, serta kesejahteraan masyarakatnya dapat terjamin. Salah satu cara meningkatkan kesejahteraan desa adalah dengan memajukan ekonomi rakyatnya. Memajukan ekonomi rakyat berarti adanya kesadaran bahwa rakyat harus disiapkan untuk membangun ekonominya. Dasar-dasar yang digunakan untuk memajukan ekonomi rakyat adalah pemberdayaan Usaha Mikro Kecil dan Menengah (UMKM) dengan konsep OPOP (One Person One Product) - OVOP (One Village One Product) - OVOC (One Village One Corporation) (Gunawan et al., 2017).

OPOP diartikan satu orang satu produk, dimana setiap orang harus menghasilkan satu produk untuk mencukupi kebutuhannya. Jika produk yang dihasilkan setiap orang terus meningkat, maka akan meningkatkan pula pendapatan setiap individu. Untuk konsep pemberdayaan OPOP (One Person One Product) ini merupakan proses bahwa setiap orang perlu adanya kesadaran akan tujuan hidup untuk mecapai tujuan kebahagiaan. Konsep yang menghasilkan dan menikmati merupakan konsep dari mekanisme pasar, setiap orang berhak untuk menikmati hasil. Di konsep OPOP ini pemilik usaha berhak menikmati hasil dari usaha yang ia bangun dan menikmati hasil yang diraihnya melalui keuntungan yang didapat dari keuntungan usahanya (Kusumawardhani \& Nuranib, 2019). 
Apabila dengan OPOP sudah berhasil, harus dikembangkan ke wilayah yang lebih luas, yaitu OVOP, satu desa satu produk unggulan yang dapat meningkatkan pendapatan wilayah dan pada gilirannya akan meningkatkan kesejahteraan warganya. Dengan adanya OVOP yang mencakup banyak orang di satu wilayah desa, usaha yang ada harus memiliki badan hukum sehingga mudah mendapatkan perlindungan dan pengembangan. Dalam hal ini, yang diperlukan adalah OVOC, dimana usaha yang sudah dilakukan oleh kumpulan orang dan komunitas dapat dikelola oleh satu perusahaan milik desa.

OVOP merupakan pendekatan program pengembangan produk unggulan daerah serta meningkatkan nilai tambah produk dalam rangka meningkatkan kesejahteraan masyarakat. Program One Village One product (OVOP) merupakan kegiatan yang dilaksanakan oleh Kementerian Koperasi dan Usaha Kecil dan Menengah Republik Indonesia yang pelaksanaannya didasari pada Inpres No. 6 Tahun 2007 Tentang Percepatan Sektor Riil dan Pembangunan Usaha Mikro Kecil dan Menengah tanggal 8 Juni 2007 yang mengamanatkan pengembangan sentra melalui pendekatan OVOP. Program ini dilakukan pada produk yang memiliki ciri khas daerah setempat atau produk yang secara kultural masyarakat yang memiliki potensi pasar baik domestik maupun pasar ekspor (Asriati, 2015).

Untuk memajukan ekonomi rakyat, yang paling penting adalah memajukan individunya. Untuk membangun individu dapat dilakukan dengan memberdayakan individu secara maksimal, sehingga setiap orang mampu bekerja dan menghasilkan suatu produk secara mandiri. Dalam hal kemandirian, berbagai gerakan dan pendidikan kewirausahaan sangatlah tepat dalam mempercepat kemandirian ekonomi rakyat. Hal tersebut merupakan suatu bentuk dukungan terhadap pemerintah untuk memperbanyak jumlah pengusaha mandiri.

Sebagaimana desa Jajarwayang Kecamatan Bojong, sebagian besar penduduknya berprofesi sebagai buruh konveksi, dimana penghasilnnya menjadi penghasilan utama rumah tangga. Selain sebagai buruh, ada juga yang berprofesi sebagai pengusaha murni, dimana proses produksi sampai pemasaran dilakukan oleh individu secara mandiri. Hal ini tentu menimbulkan berbagai anggapan bahwa desa Jajarwayang memiliki potensi ekonomi lokal yang perlu dikembangkan agar dapat menghasilkan OVOP. Dengan mayoritas sebagai buruh, tentu menimbulkan potensi dimana usaha tersebut seharusnya dapat dikembangkan menjadi usaha mandiri sehingga dapat meningkatkan kesejahteraan masyarakatnya. Selain itu, timbul pula berbagai pernyataan bahwa dengan banyaknya usaha konveksi, memiliki kain perca (kain sisa hasil konveksi) yang bagi sebagian orang tidak dimanfaatkan. Secara ekonomi, kain perca tersebut dapat dimanfaatkan sebagai kerajinan misalnya, ataupun barang lain yang dapat menghasilkan nilai ekonomi lebih. Hal ini tentu saja dapat menjadi penunjang menuju terbentuknya OVOP di Desa Jajarwayang Kecamatan Bojong untuk selanjutnya dapat dibentuk OVOC.

OVOC merupakan program dengan memadukan konsep kawasan komoditas unggulan, yang pertama kali dikembangkan di Provinsi Oita Jepang, dengan menggerakan program satu desa satu komoditas, dan sukses mengangkat harkat desa miskin Oyama karena adanya hasil pertanian unggulan meskipun dengan skala kecil.

Oleh karena itu, berdasarkan penjelasan di atas, perlu adanya pemetaan berupa jumlah penduduk yang bekerja sebagai pengusaha konveksi, buruh konveksi, ataupun usaha lain, latar belakang dari usaha yang dilakukan, serta potensi dan kendala apa saja yang timbul di Desa Jajarwayang Kecamatan Bojong agar selanjutnya dapat dilakukan langkah-langkah yang tepat guna menuju terbentuknya OVOP dan OVOC (Harmiati et al., n, 2017.) .

Tujuan dari penelitian ini adalah 1) mengidentifikasi kondisi ekonomi masyarakat di desa Jajarwayang berdasarkan data-data yang didapatkan penulis. 2) mengidentifikasi permasalahan ekonomi di desa Jajarwayang sehingga bisa didapatkan solusi dari problem 
ekonomi yang terjadi. 3) membuat strategi untuk meningkatkan ekonomi kreatif di Desa Jajarwayang Kecamatan Bojong ke depan.

\section{METODE}

Penulis mengambil bahan dari berbagai sumber, yang kemudian dibagi dalam 2 sumber. Sumber pertama diambil dari data-data primer, data primer langsung dari kepala desa Jajarwayang Kecamatan Bojong, disana tercatat dengan rapi dan komprehensif. Penulis mengolah data primer dari hasil observasi dan wawancara secara langsung dengan objek penelitian (kepala desa, masyarakat, dan pekerja). Kemudian sumber data yang ke-2 penulis ambil dari berbagai referensi buku dan jurnal penelitian yang berkaitan dengan penelitian ini.

Metode peneilitian ini menggunakan social mapping (pemetaan sosial). Pemetaan sosial (social mapping) didefinisikan sebagai proses penggambaran masyarakat yang sistematik serta melibatkan pengumpulan data dan informasi mengenai masyarakat termasuk di dalamnya profil dan masalah sosial yang ada pada masyarakat tersebut (Mellita \& Erlansyah, 2014).

Pemetaan sosial ini penulis anggap pendekatan yang cocok untuk digunakan dalam penelitian ini, karena dari pendekatan social mapping akan didapatkan informasi yang komprehensif, dan hasil dari pemetaan akan digunakan untuk tujuan penilitian selanjutnya membuat strategi peningkatan ekonomi di Desa Jajarwayang Kecamatan Bojong.

\section{HASIL DAN PEMBAHASAN}

a. Pendataan Masalah dan Potensi Ekonomi

Pendataan ini dilakukan dengan mencari data mata pencaharian penduduk Desa Jajarwayang Kecamatan Bojong di Balaidesa Jajarwayang. Setelah mendapatkan data, kemudian kami melakukan wawancara kepada masyarakat desa Jajarwayang untuk melengkapi data yang dibutuhkan, seperti lamanya usaha, masalah yang dihadapi dalam usaha dan sebagainya.

b. Analisis Kebutuhan

Setelah mendapatkan data yang dibutuhkan, perlu diadakan analisis terhadap masalah yang ada untuk kemudian diambil langkah-langkah apa yang perlu dilakukan untuk mewujudkan Capacity Building sebagai Langkah Pendayagunaan Limbah Industri di Desa Jajarwayang Kecamatan Bojong.

1) Pendataan masalah dan potensi industri kreatif

Pendataan dilakukan dengan wawancara kepada pihak desa mengenai industri kreatif yang ada di Desa Jajarwayang Kecamatan Bojong. Adapun survey awal kepada pihak desa mendapat hasil sebagai berikut:

Profesi yang ada Desa Jajarwayang kecamatan bojong adalah sebagai petani, buruh tani, pedagang, pengusaha konveksi, buruh konveksi, pedagang keliling, montir, TNI, POLRI, pensiunan, karyawan swasta, pengusaha kecil dan menengah. Adapun jumlah dari masing-masing profesi tidak dapat disebutkan karena data terakhir di desa adalah tahun 2014, sehingga data yang valid untuk saat ini belum ada. (wawancara, badriyah, 2020)

Kemudian setelah melakukan wawancara kepada pihak desa, penulis melakukan survey ke lapangan, yaitu ke 4 RW, dan 16 RT. Adapun hasil yang didapat mengenai industri kreatif sebagai berikut: 
Tabel 1. Data Pemetaan Industri Kreatif di Desa Jajarwayang Kecamatan Bojong

\begin{tabular}{|c|c|c|c|c|}
\hline RW & RT & $\begin{array}{c}\text { Jumlah Buruh } \\
\text { konveksi }\end{array}$ & $\begin{array}{c}\text { Jumlah Pengusaha } \\
\text { konveksi }\end{array}$ & $\begin{array}{c}\text { Jumlah Pengusaha } \\
\text { Tempe }\end{array}$ \\
\hline $\mathrm{K}$ & RT 1 & 4 & \multirow{4}{*}{ 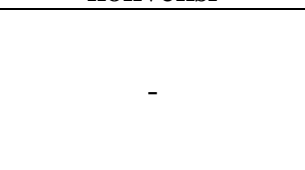 } & \multirow{4}{*}{7 Produsen } \\
\hline \multirow{3}{*}{$\begin{array}{l}\text { RW } 1 \\
\mathrm{~m}\end{array}$} & RT 2 & 6 & & \\
\hline & RT 3 & 10 & & \\
\hline & RT 4 & 3 & & \\
\hline \multirow{3}{*}{$\stackrel{\mathrm{d}}{\mathrm{RW}} 2$} & RT 5 & 1 & \multirow{5}{*}{1} & \multirow{4}{*}{2 Produsen } \\
\hline & RT 6 & 4 & & \\
\hline & RT 7 & 4 & & \\
\hline $\mathrm{a}$ & RT 8 & 4 & & \\
\hline $\mathrm{n}$ & RT 9 & 20 & & \multirow{4}{*}{5 Produsen } \\
\hline RW 3 & RT 10 & 4 & \multirow{4}{*}{2} & \\
\hline & RT 11 & 5 & & \\
\hline $\mathrm{p}$ & RT 12 & 2 & & \\
\hline $\mathrm{e}$ & RT 13 & - & & \multirow{4}{*}{1 Produsen } \\
\hline \multirow{3}{*}{$\begin{array}{l}\mathrm{R} W 4 \\
\mathrm{e}\end{array}$} & RT 14 & 10 & \multirow[t]{3}{*}{6} & \\
\hline & RT 15 & 11 & & \\
\hline & RT 16 & - & & \\
\hline
\end{tabular}

Kemudian peneliti menklasifikasi ke dalam 3 bentuk industri kreatif yang banyak menjadi sumber perekonimian masyarakat desa Jajarwayang, 3 klasifikasi itu adalah:

Tabel 2. Klasifikasi Industri Kreatif di Desa Jajarwayang Kecamatan Bojong

\begin{tabular}{|c|c|}
\hline KATEGORI & KETERANGAN \\
\hline $\begin{array}{l}\text { PEMBUAT } \\
\text { JEANS }\end{array}$ & $\begin{array}{l}\text { Terdapat } 7 \text { lokasi pembuat celana jeans, dari semua titik tersebut dimiliki } \\
\text { oleh owner yang sudah mapan, industri kreatif ini mampu membuat } \\
\text { lowongan pekerjaan bagi masyarakat sekitar }\end{array}$ \\
\hline $\begin{array}{l}\text { BURUH } \\
\text { KONVEKSI }\end{array}$ & $\begin{array}{l}\text { Masyarakat dilingkungan Jajarwayang mempunyai keahlian untuk } \\
\text { memproduksi pakaian, (baju, celana, gamis), data ini didapatkan langsung } \\
\text { oleh peneliti dari bebrapa buruh. Mereka mengambil job (sanggan) baik dari } \\
\text { dalam desa Jajarwayang maupun dari luar. }\end{array}$ \\
\hline $\begin{array}{l}\text { PENYEDIA } \\
\text { MAKANAN } \\
\text { (TEMPE) }\end{array}$ & $\begin{array}{l}\text { Klasifikasi yang terakhir adalah penyedia makanan tempe, klaster ini } \\
\text { termasuk } 3 \text { besar dari industri kreatif yang ada di Jajarwayang, lebih dari } 6 \\
\text { sampai } 7 \text { pengusaha penyedia tempe dengan cara memproduksi sendiri, } \\
\text { umkm tempe ini masih menggunakan manual tanpa ada campur tangan } \\
\text { mesin, meski produksi mereka bagus, tetapi harus bersaing harga dengan } \\
\text { penyededia makanan tempe yang lain. }\end{array}$ \\
\hline
\end{tabular}

2) Analisis kebutuhan

Dari data di atas menyatakan bahwa masyarakat desa Jajarwayang sebagian besar bekerja sebagai buruh konveksi, dimana buruh tersebut dibagi menjadi buruh dalam skala kecil dan buruh dalam skala besar. Buruh dalam skala kecil biasanya mengambil bahan untuk dijahit sendiri dirumah, sedangkan buruh dalam skala besar biasanya mengambil bahan dalam jumlah banyak kemudian membuka lapangan pekerjaan untuk orang lain, artinya disisi lain ia bertindak sebagai bos tetapi masih ada bosnya lagi di atasnya.

Dari banyaknya buruh konveksi, informasi yang didapat adalah mereka bekerja sebagai buruh untuk memenuhi kebutuhan hidupnya serta sebagai penghasilan utama keluarga.

Potensi dari buruh konveksi ini adalah banyaknya kain percah yang kurang memiliki nilai ekonomi. Masyarakat biasanya menjual kain percah yang ada dengan harga Rp. 5.000,- sampai Rp. 7.000,- per kilogramnya kepada pengumpul kain percah. Kain percah yang dihasilkan berupa potongan-potongan kecil sehingga sulit 
untuk dimanfaatkan kembali. Selain itu, juga ada pula yang hanya dibuang di pingir sungai. Dalam hal ini, masyarakat sudah memanfaatkan semua yang ada sehingga tidak ada bahan yang sia-sia. Namun, kain percah tersebut seharusnya dapat dikembangkan menjadi bahan yang nilainya lebih dari hanya sekedar dijual ke pengumpul. Perlu adanya edukasi dan pelatihan pemanfaatan kain perca tersebut, sehingga selain mendapat penghasilan sebagai buruh ia juga mendapat penghasilan dari bidang lain. Berikut dokumentasi pekerja konveksi:

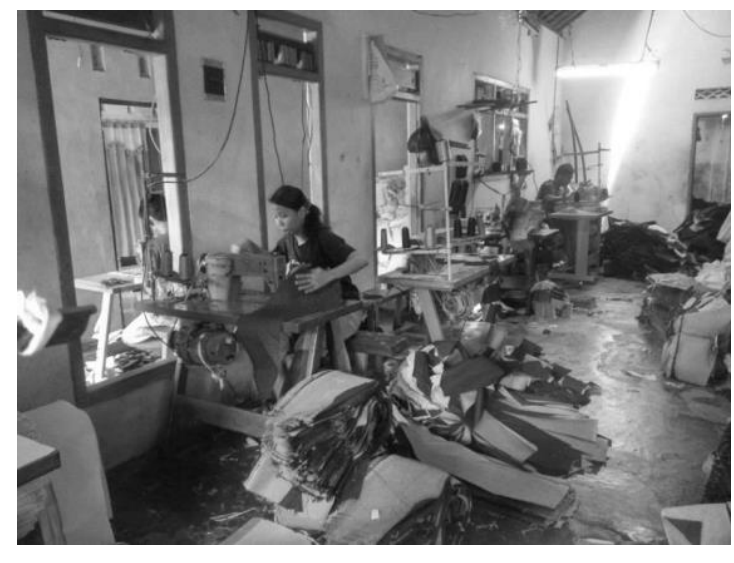

Gambar 1. Usaha Jeans

Berbagai permasalahan di desa Jajarwayang secara umum masih seputar pembangunan sarana dan prasarana dalam bentuk fisik dan bidang lain seperti pembangunan modal dalam bidang ekonomi yang masih kurang, permasalahan desa merupakan hal yang tercapai melalui pembangunan jangka menengah yang dijabarkan dalam rencana pembangunan secara bertahap dengan skala prioritas yang mendesak. Di desa Jajarwayang permasalahan secara umum dijabarkan sebagai berikut:

a. Keterbatasan Dana

Dana merupakan salah satu faktor penentu terlaksana dan tidaknya suatu perencanaan. Pelaksanaan perencanaan pembangunan dapat dipastikan tidak dapat terealisasi tanpa adanya dana.

b. Keterbatasan Sumber Daya

Pelaksanaan perencanaan pembangunan baik fisik maupun non fisik juga dipengaruhi oleh faktor sumber daya, baik sumber daya alam maupun sumber daya manusia. Sumber daya alam seperti tidak tersediannya bahan baku, sedangkan sumber daya manusia berkaitan dengan kurangnya tenaga ahli dan ketidakmampuan dari pelaku-pelaku pelaksana pembangunan di desa untuk melaksanakan pembangunan.

c. Bidang Ekonomi

1) Belum adanya pengembangan terhadap potensi ekonomi desa.

2) Adanya kemacetan dalam simpan pinjam khususnya dana PNPM.

3) Terbatasnya dana untuk modal.

4) Belum adanya pendidikan keterampilan bagi masyarakat.

5) Pemanfaatan rentenir oleh sebagian masyarakat.

Setelah mendapatkan data yang dibutuhkan, perlu diadakan analisis terhadap masalah yang ada untuk kemudian diambil strategi apa yang perlu dilakukan untuk mewujudkan Capacity Building sebagai Langkah Pendayagunaan Industri kreatif dan limbahnya di Desa Jajarwayang Kecamatan Bojong.

Pertama peneliti menggunakan teori Capacity Building, teori ini merupakan pengembangan kapasitas keahlian/kemampuan yang dimiliki masyarakat untuk menciptakan 
sumber ekonomi baru melalui ekonomi kreatif. Capacity building dapat pula dimaknai sebagai proses kreatif dalam membangun kapasitas yang belum nampak. Dalam hal ini, penulis akan memberikan sosialisasi dan pelatihan tentang pemanfaatan limbah indsutri menjadi kerajinan yang bernilai ekonomi (Jenivia Dwi Ratnasari, Mochamad Makmur, 2016).

Kemudian yang kedua menggunakan Institusional Building, yaitu menjalin kerjasama dengan institusi yang dapat membantu mengembangkan usaha seperti kemudahan mendapatkan modal, dan memudahkan dalam pemasaran. Dalam hal ini kerjasama dengan lembaga yang terkait seperti koperasi dan lain-lain sangat penting untuk menunjang keberhasilan usaha.

\section{KESIMPULAN}

Kesimpulan berupa paragraf dan harus mengindikasi secara jelas hasil-hasil yang diperoleh, Desa Jajarwayang merupakan salah satu desa yang berpotensi mencapai OVOP (One Village One Product), dimana masyarakatnya yang mayoritas berprofesi sebagai buruh konveksi menghasilkan kain percah yang dapat dibuat barang bernilai jual lebih tinggi daripada hanya sekedar dijual kepada pengumpul. Dalam mencapai OVOP tentu saja harus didukung oleh kemampuan sumber daya manusianya, dengan cara memberikan pelatihan dan edukasi agar dapat mengembangkan potensi yang ada. Banyaknya potensi yang tersedia belum sepenuhnya disadari dan dimanfaatkan oleh masyarakat, sehingga perlu adanya pendampingan dan pengedukasian untuk memotivasi masyarakat mengembangkan sisa industri menjadi produk yang bernilai jual. Potensi ekonomi kreatif di desa Jajarwayang antara lain, produsen jeans, buruh pakaian, dan produsen tempe, semuanya memiliki masalah dalam hal pengembangan, permodalan, dan SDM. Peneliti mengusulkan untuk menggunakan strategi capacity building dan institusional building, untuk memajukan ekonomi kreatif di desa Jajarwayang.

\section{DAFTAR PUSTAKA}

Asriati, N. (2015). Pengembangan Kawasan Terpadu Mandiri Dengan Pendekatan Model One Village One Product (Ovop) Daerah Transmigrasi Rasau Jaya. Jurnal Economia, 11(1), 72. https://doi.org/10.21831/economia.v11i1.7757

Gunawan, A., Katili, P. B., \& Lestari, M. (2017). Pemetaan Potensi Industri Kreatif Unggulan Untuk Meningkatkan Pertumbuhan Ekonomi. Journal Industrial Servicess, 3(1), 203209. http://jurnal.untirta.ac.id/index.php/jiss/article/view/2086

Gunawan Sumodiningrat \& Ari Wulandari. (2015). Menuju Ekonomi Berdikari

(Pemberdayaan UMKM dengan Konsep OPOP - OVOP - OVOC).

Harmiati, D., Si, M., Zulhakim, A. A., \& Sos, S. (n.d.). Eksistensi Badan Usaha Milik Desa (Bumdes) Dalam Mengembangkan Usaha Dan Ekonomi Masyarakat Desa Yang Berdaya Saing Di Era Masyarakat Ekonomi Asean Oleh. Retrieved June 13, 2021, from http://m.kbr.id/muhamad_ridlo_susanto/01-

Jenivia Dwi Ratnasari, Mochamad Makmur, H. R. (2016). Pengembangan Kapasitas (Capacity Building) Kelembagaan Pada Badan Kepegawaian Daerah Kabupaten Malang. Jurnal Administrasi Publik Mahasiswa Universitas Brawijaya, 1(3), 103-110.

Kusumawardhani, R. T., \& Nuranib, F. (2019). Peningkatan Pemberdayaan UMKM Kreatif Dalam Pembangunan Ekonomi Ideal Indonesia. Blog.Ub.Ac.Id. http://blog.ub.ac.id/rezatitanika/files/2019/12/JURNAL-ADM-PEMBANGUNAN.pdf

Mellita, D., \& Erlansyah, D. (2014). Pemetaan Industri Kreatif Dalam Meningkatkan Pertumbuhan Ekonomi Kawasan Urban Di Kota Palembang. Prosiding Economic Globalization Trend \& Risk Developing Country, 1-13. http://eprints.binadarma.ac.id/2073/1/FP_20.pdf. 